\title{
Emergence of T cell immunosenescence in diabetic chronic kidney disease
}

Yen-Ling Chiu ${ }^{1,2,3}$, Wan-Chuan Tsai ${ }^{2,4}$, Ruo-Wei Hung ${ }^{2}$, I-Yu Chen², Kai-Hsiang Shu ${ }^{2,5}$, Szu-Yu Pan², Feng-Jung Yang ${ }^{6}$, Te-Tien Ting ${ }^{7}$, Ju-Ying Jiang ${ }^{8+}$, Yu-Sen Peng ${ }^{2,9,10+}$ and Yi-Fang Chuang ${ }^{11^{*+}}$

\begin{abstract}
Background: Type 2 diabetes is an important challenge given the worldwide epidemic and is the most important cause of end-stage renal disease (ESRD) in developed countries. It is known that patients with ESRD and advanced renal failure suffer from immunosenescence and premature T cell aging, but whether such changes develop in patients with less severe chronic kidney disease (CKD) is unclear.

Method: 523 adult patients with type 2 diabetes were recruited for this study. Demographic data and clinical information were obtained from medical chart review. Immunosenescence, or aging of the immune system was assessed by staining freshly-obtained peripheral blood with immunophenotyping panels and analyzing cells using multicolor flow cytometry.
\end{abstract}

Result: Consistent with previously observed in the general population, both $\mathrm{T}$ and monocyte immunosenescence in diabetic patients positively correlate with age. When compared to diabetic patients with preserved renal function (estimated glomerular filtration rate $>60 \mathrm{ml} / \mathrm{min}$ ), patients with impaired renal function exhibit a significant decrease of total $\mathrm{CD}^{+}$and $\mathrm{CD} 4^{+} \mathrm{T}$ cells, but not $\mathrm{CD} 8^{+} \mathrm{T}$ cell and monocyte numbers. Immunosenescence was observed in patients with CKD stage 3 and in patients with more severe renal failure, especially of $\mathrm{CD} 8^{+} \mathrm{T}$ cells. However, immunosenescence was not associated with level of proteinuria level or glucose control. In age, sex and glucose level-adjusted regression models, stage 3 CKD patients exhibited significantly elevated percentages of $\mathrm{CD}^{-} 8^{-}, \mathrm{CD} 127^{-}$, and $\mathrm{CD} 57^{+}$cells among $\mathrm{CD}^{+} \mathrm{T}$ cells when compared to patients with preserved renal function. In contrast, no change was detected in monocyte subpopulations as renal function declined. In addition, higher body mass index (BMI) is associated with enhanced immunosenescence irrespective of CKD status.

Conclusion: The extent of immunosenescence is not significantly associated with proteinuria or glucose control in type 2 diabetic patients. T cells, especially the $\mathrm{CD} 8^{+}$subsets, exhibit aggravated characteristics of immunosenescence during renal function decline as early as stage 3 CKD. In addition, inflammation increases since stage 3 CKD and higher $\mathrm{BMI}$ drives the accumulation of $\mathrm{CD} 8^{+} \mathrm{CD} 57^{+} \mathrm{T}$ cells. Our study indicates that therapeutic approaches such as weight loss may be used to prevent the emergence of immunosenescence in diabetes before stage 3 CKD.

Keywords: Immunosenescence, CKD, T cell, Diabetes, BMI

\footnotetext{
* Correspondence: chuangy@ym.edu.tw

${ }^{\dagger} J u-Y i n g$ Jiang, Yu-Sen Peng and Yi-Fang Chuang contributed equally to this

work.

${ }^{11}$ Institute of Public Health, School of Medicine, National Yang-Ming

University, Taipei, Taiwan

Full list of author information is available at the end of the article
}

(C) The Author(s). 2020 Open Access This article is licensed under a Creative Commons Attribution 4.0 International License, which permits use, sharing, adaptation, distribution and reproduction in any medium or format, as long as you give appropriate credit to the original author(s) and the source, provide a link to the Creative Commons licence, and indicate if changes were made. The images or other third party material in this article are included in the article's Creative Commons licence, unless indicated otherwise in a credit line to the material. If material is not included in the article's Creative Commons licence and your intended use is not permitted by statutory regulation or exceeds the permitted use, you will need to obtain permission directly from the copyright holder. To view a copy of this licence, visit http://creativecommons.org/licenses/by/4.0/ The Creative Commons Public Domain Dedication waiver (http://creativecommons.org/publicdomain/zero/1.0/) applies to the data made available in this article, unless otherwise stated in a credit line to the data. 


\section{Introduction}

Diabetic kidney disease is a growing, worldwide public health epidemic. There are more than 415 million people suffering from diabetes worldwide, and it is estimated that more than $40 \%$ of these patients will develop chronic kidney disease (CKD), creating a huge health care burden $[1,2]$. Beyond the burden of care for renal failure itself, diabetic kidney disease increases the risk for other comorbidities, especially cardiovascular disease (CVD) [3] and infection [4]. Unfortunately, despite much progress in the treatment of hypertension and hyperlipidemia to reduce CVD, the prevalence of CVD in diabetic patients with renal failure remains excessively high [5]. Patients with type 2 diabetes are also at higher risk for infections of the skin and soft tissue, genitourinary, gastrointestinal and respiratory tracts [6], and are twice as likely to be hospitalized for infectious disease management than non-diabetics. Overall, the prevalence of diabetics and diabetic complications is expected to continue rising due to the increasing predominance of obesity and advanced age in the human population.

Immune mechanisms are increasingly being recognized as important factors in the development of various agingassociated chronic conditions [7, 8]. During normal aging, the continuous interaction between the host and environment results in accumulating changes in the immune system, which is collectively referred to as immunosenescence $[9,10]$. This complex process of immune aging leads to increases in specific changes in $\mathrm{T}$ cell and monocyte populations and is found to be significantly enhanced in individuals with chronic diseases associated with inflammation [11], such as end-stage renal disease [12, 13] and rheumatoid arthritis [14].

As the host encounters antigens, there is a progressive decrease in naïve $T$ cells and concomitant increase in memory $\mathrm{T}$ cells of the effector phenotype [15]. Over time, $\mathrm{T}$ cells gradually lose the expression of CD28 and CD27 costimulatory molecules as well as the hemostatic cytokine receptor CD127 from their surface. The loss of naïve $T$ cells leads to decreased vaccine responses and poor control of newly encountered pathogens [16]. On the other hand, the accumulation of memory $\mathrm{T}$ cells is highly proinflammatory and these cells acquire the expression of senescent cell markers such as CD57 and KLRG1. Moreover, these advanced effector T cells with increased production of proinflammatory cytokines and adhesion molecules are more easily recruited to the vascular epithelium, which may lead to the development of atherosclerotic CVD [17, 18].

In addition to $\mathrm{T}$ lymphocytes, monocytes in the peripheral blood also exhibit changes during aging. In humans, circulatory $\mathrm{CD} 8^{+}$monocytes can be separated into three major subsets based on their $\mathrm{CD} 14$ and $\mathrm{CD} 16$ expression. The percentage of proinflammatory $\mathrm{CD} 14^{+} \mathrm{CD} 16^{+}$monocytes reportedly increases with age and correlates with cardiovascular mortality $[19,20]$. We recently developed a comprehensive aging-related immune profile based on both lymphocytes and monocytes and demonstrated that aggravated immunosenescence is positively associated with CVD in end-stage renal disease (ESRD) patients [21]. Furthermore, a collective aging-related immune matrix derived from a 9-year longitudinal study of innate and adaptive immunity markers was found to be predictive of all-cause mortality beyond the well-established risk factors listed in the Framingham Heart Study [22]. Thus, immunosenescence is an important phenomenon of aging that requires further understanding including of the development of agingrelated diseases and cardiovascular complications. In this manuscript, we investigated whether patients with type 2 diabetes exhibit significant changes related to immunosenescence with age and if these changes develop as renal function declines.

\section{Methods \\ Participants}

All study participants were recruited from the Far Eastern Memorial Hospital outpatient clinic between January and December of 2018. Only individuals diagnosed with type 2 diabetes for more than 6 months and older than 20 years were enrolled. The average age was $62 \pm 10.3$ years and mean duration of diagnoses of diabetes was 10 years. Patients who had been hospitalized in the 3 months prior to the study or who were diagnosed with active cancer were excluded. The study protocol was proved by the institutional review board of the Far-Eastern Memorial Hospital (FEMH 107032-F).

\section{Data collection and laboratory exams}

Clinical data were collected by trained study assistants and peripheral blood was collected on the day of informed consent. Through history taking and detailed chart reviews, baseline co-morbidities and clinical laboratory data were recorded. All clinical laboratory exams including high sensitivity C-reactive protein (hs-CRP) nephelometry (Siemens) were tested in the core laboratory of the Far Eastern Memorial Hospital on the day of blood collection. Renal function was assessed using eGFR (estimated glomerular filtration rate), which was calculated using the CKD-EPI formula based on serum creatinine level. Patients were separated into three different groups: patients with normal eGFR $>60 \mathrm{ml} / \mathrm{min}(n=379)$, patients with stage 3 CKD $(n=110$, eGFR between 30 and $60 \mathrm{ml} / \mathrm{min}$ ), and patients with stage 4 or stage 5 CKD ( $n=34$, eGFR less than $30 \mathrm{ml} / \mathrm{min})$.

\section{Peripheral blood immunophenotyping}

Immediately after blood collection, $100 \mu \mathrm{l}$ of whole blood was immediately stained with the lymphocyte or 
monocyte panel and results were acquired using a Beckman Coulter CytoFLEX multicolor flow cytometer on the same day. For the lymphocyte panel, CD45-KrO (clone J33, Beckman Coulter) was used to identify leukocytes and CD3-AF700 (clone UCHT1, Biolegend) was used to identify $\mathrm{CD}^{+} \mathrm{T}$ cells from the lymphocytes gated by forward and side scatter properties. $\mathrm{CD}_{4}^{+}$and $\mathrm{CD}^{+} \mathrm{T}$ cells were stained with CD4-BUV405 and CD8APC/Cy7 antibodies (clone RPA-T4, BD and SK1, Biolegend). $\mathrm{T}$ cell differentiation states were determined by staining with CD27-PE/Cy7 and CD45RO-Alexa488 antibodies (clone O323 and UCHL1, Biolegend). Additional phenotypic markers were identified with CD28-BV421 (clone CD28.2, Biolegend), CD57-APC (clone HCD57, Biolegend), and CD127-PE (clone eBioRDR5, eBioscience) antibodies.

After gating on forward/side scatter and CD45, as in the lymphocyte panel, total monocytes were first identified by staining with CD86-PE antibody (clone IT2.2, eBioscience), and were further classified as classical $\left(\mathrm{CD} 14^{++} \mathrm{CD} 16^{-}\right)$, intermediate $\left(\mathrm{CD} 14^{++} \mathrm{CD} 16^{+}\right)$, and non-classical $\left(\mathrm{CD} 14^{+} \mathrm{CD} 16^{++}\right)$ subsets by staining with CD14-FITC and CD16-APC/ Cy7 antibodies (clone M5E2 and clone 3G8, both from Biolegend).

Absolute cell number counting based on the fluidics of the cytometer was performed according to manufacturer's protocol (CytoFLEX, Beckman Coulter) following the quality assurance procedure.

\section{Statistical analyses}

Patient characteristics and immunophenotyping results are described as mean \pm standard deviation for continuous variables and frequency for categorical variables. These variables were analyzed by analysis of variance (ANOVA) and Chi-square test, respectively, when compared between groups of different renal function. Pearson correlation was applied to evaluate the correlation of age with immune cell subset frequencies and absolute cell numbers. Multivariate linear regression models with immunophenotyping results as the dependent variable, adjusting for age and gender, were used to investigate the associations between renal function and immunophenotyping results. Trend analysis was also conducted to investigate the linear trend between immunophenotyping and stages of CKD. All statistical tests were twotailed, and a $p$ value of less than 0.05 was considered significant. The statistical analyses were performed with STATA version 15.1 (StataCorp).

\section{Results}

Age-related immune changes identified in type 2 diabetic patients

We first analyzed the relationship between age and immune cell numbers as well as frequencies. Supplementary
Figure 1 shows a representative multicolor flow cytometry experiment. As shown in Fig. 1a and supplementary Table 1, a progressive decrease in total $\mathrm{CD}^{+} \mathrm{T}$ cell numbers as well as $\mathrm{CD}_{4}^{+}$and $\mathrm{CD} 8^{+} \mathrm{T}$ cells were noted with advancing age. However, the total number of $\mathrm{CD}^{+} 8^{+}$ monocytes did not change with age (Fig. 1d). T cell differentiation was determined by the pattern of CD27 and CD45RO expression as well as through analysis of additional markers associated with aging (CD127, CD27, $\mathrm{CD} 28$ and $\mathrm{CD} 57$ ). The classification of progressive $\mathrm{T}$ cell differentiation status based on $\mathrm{CD} 27$ and $\mathrm{CD} 45 \mathrm{RO}$ is as follows: Naïve $\mathrm{T}$ cells $\left(\mathrm{T}_{\mathrm{NAIVE}}\right)$ : $\mathrm{CD} 27^{+} \mathrm{CD} 45 \mathrm{RO}^{-}$; central memory $\mathrm{T}_{\mathrm{CM}}$ cells: $\mathrm{CD} 27^{+} \mathrm{CD} 45 \mathrm{RO}^{+}$; effector memory $\mathrm{T}_{\mathrm{EM}}$ cells: $\mathrm{CD} 27^{-} \mathrm{CD} 45 \mathrm{RO}^{+}$; and the most differentiated effector $\mathrm{T}_{\mathrm{E}}$ cell subset: $\mathrm{CD}^{2} 7^{-} \mathrm{CD} 45 \mathrm{RO}^{-}$. When the subset composition of $\mathrm{CD}^{+}$and $\mathrm{CD}^{+} \mathrm{T}$ cells (Fig. $1 \mathrm{~b}$ and $\mathrm{c}$ ) was analyzed, there was a significant progressive loss of naïve $\mathrm{T}$ cells and increase of memory cells (effector memory $\mathrm{T}_{\mathrm{EM}}$ and effector $T_{E}$ subsets) with age, which is consistent with reported findings in healthy individuals. Furthermore, the homeostatic $\mathrm{CD} 127^{+}$(IL-7 receptor) subset was found to decrease with age, while $\mathrm{CD}_{28}^{-}, \mathrm{CD}^{-} 7^{-}$, and $\mathrm{CD} 57^{+}$senescent cell subsets increased with age. Proinflammatory $\mathrm{CD} 14^{++} \mathrm{CD} 16^{+}$and non-classical $\mathrm{CD} 14^{+} \mathrm{CD} 16^{++}$monocytes also increased in frequency with age, albeit to a much lesser extent than the changes seen in lymphocytes. These findings are compatible with the general immunosenescence changes associated with aging.

\section{Patient characteristics in different estimated glomerular filtration rate (eGFR) groups}

To understand if patients with diabetic kidney disease exhibit more immunosenescence features than patients with normal renal function, participants were separated into three groups: patients with normal eGFR $>60 \mathrm{ml} /$ min, patients with stage 3 CKD (eGFR between 30 and $60 \mathrm{ml} / \mathrm{min}$ ), and patients with stage 4 or stage 5 CKD (eGFR less than $30 \mathrm{ml} / \mathrm{min}$ ). Clinical characteristics of the three groups including their glucose control and medications were compared and are shown in Table 1. Patients with impaired renal function were older than patients with preserved renal function. As expected, patients with stage 4/5 CKD had an average eGFR of 19.6 $\mathrm{ml} / \mathrm{min}$ and decreased serum albumin levels compared to the other two groups. Blood sugar was slightly higher for patients with stage 3 CKD than other groups, as was systemic inflammation, as measured by hs-CRP. Furthermore, there was a higher percentage of insulin use and lower percentage of sulfonylurea usage among patients with stage 4/5 CKD.

Relationship between CKD status and immunosenescence We next examined the immunosenescence profile of each patient group (Table 2). Total $\mathrm{CD}^{+}$and $\mathrm{CD}^{+}{ }^{+} \mathrm{T}$ 


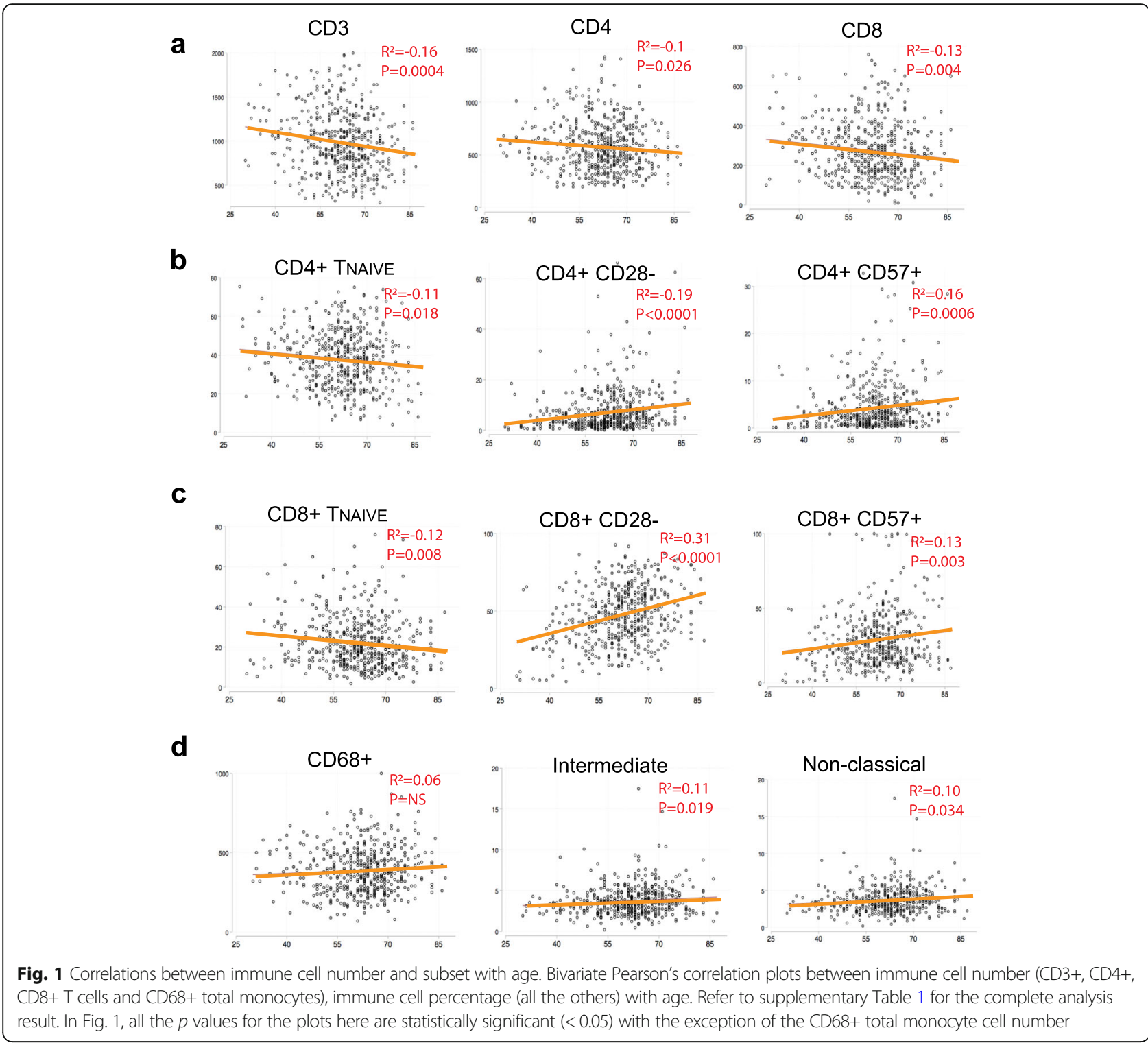

cell numbers decreased with more severe CKD, reminiscent of aging and patients on hemodialysis [21]. Although no decrease in naïve $\mathrm{CD}^{+}$or $\mathrm{CD}^{+} \mathrm{T}$ cells was found, there was a significant decrease of $\mathrm{CD} 127^{+} \mathrm{T}$ cells in both the $\mathrm{CD}^{+}$and $\mathrm{CD} 8^{+}$compartments. $\mathrm{CD} 8^{+}$ effector cells, both $\mathrm{CD} 28^{-}$and $\mathrm{CD} 57^{+}$subsets, significantly increased in the two CKD groups compared to individuals with normal eGFR. Unexpectedly, no changes in monocyte subset distribution were detected between groups.

\section{Independent association between CKD and immunosenescence}

Next, we analyzed the independent effect of CKD on immunosenescence in age and gender-adjusted regression models (Table 3). There was a significant decrease in $\mathrm{CD}^{+}$and $\mathrm{CD}_{4}^{+} \mathrm{T}$ cells between patients with stage $4 / 5$
CKD and patients with normal eGFR. In addition, stage 4/ 5 CKD patients exhibited lower percentages of $\mathrm{CD} 4^{+} \mathrm{CD} 127^{+}$cells. Phenotypically, $\mathrm{CD} 8^{+}$subset changes were more pronounced than CD4+ cells. Among CD8+ T cells, the $\mathrm{CD} 127^{+}$subset was decreased and percentages of $\mathrm{CD} 28^{-}$as well as $\mathrm{CD} 57^{+}$cells were increased. There was a significant trend that as CKD stages increased, percentages of $\mathrm{CD}_{4}^{+} \mathrm{CD} 127^{+}$cells, CD8 $+\mathrm{T}_{\mathrm{NAIVE}}$ cells, and $\mathrm{CD} 8^{+} \mathrm{CD} 127^{+}$cells decreased while percentages of effector $\mathrm{CD} 8+\mathrm{T}_{\mathrm{E}}$ cells, $\mathrm{CD} 8^{+} \mathrm{CD} 28^{+}$cells, and $\mathrm{CD} 8^{+} \mathrm{CD} 57^{+}$cells increased (Table 3 ). In the analysis, although age was adjusted in the multivariable-adjusted model, patients with normal eGFR were significantly younger than patients with CKD. To eliminate the concern of residual confounding effects of age, we further used the nearest neighbor matching to generate an age-matched sample of patients 
Table 1 Baseline demographics, clinical, and laboratory measurements stratified by CKD stage based on eGFR

\begin{tabular}{|c|c|c|c|c|}
\hline & eGFR $\geq 60(n=379)$ & Stage 3 CKD $(n=110)$ & Stage $4 / 5$ CKD $(n=34)$ & $p$ value \\
\hline eGFR (ml/min) & $88.3(15.4)$ & $48.0(8.0)$ & $19.7(7.4)$ & $<0.001^{*}$ \\
\hline Age (yr) & $59.9(10.1)$ & $67.7(8.6)$ & $67.1(8.2)$ & $<0.001^{*}$ \\
\hline Male (\%) & $197(52.0)$ & $61(55.5)$ & $26(76.5)$ & 0.022 \\
\hline Systolic BP (mmHg) & $130.5(16.5)$ & $135.4(16.8)$ & $132.8(13.5)$ & 0.019 \\
\hline Diastolic BP (mmHg) & $71.9(11.6)$ & $70.4(12.8)$ & $70.4(11.2)$ & 0.44 \\
\hline Albumin (g/dl) & $4.5(0.3)$ & $4.4(0.3)$ & $4.1(0.5)$ & $<0.001^{*}$ \\
\hline Creatinine $(\mathrm{mg} / \mathrm{dl})$ & $0.8(0.2)$ & $1.4(0.3)$ & $3.6(2.0)$ & $<0.001^{*}$ \\
\hline HbA1c (\%) & $7.2(1.0)$ & $7.3(1.1)$ & $7.1(1.0)$ & 0.41 \\
\hline AC sugar $(\mathrm{mg} / \mathrm{dl})$ & $137.7(37.4)$ & $145.9(61.6)$ & $124.7(31.6)$ & $0.034^{*}$ \\
\hline Use of insulin (\%) & $93(24.5)$ & $49(44.5)$ & $22(64.7)$ & $<0.001^{*}$ \\
\hline Use of sulfonylurea (\%) & $167(44.1)$ & $46(41.8)$ & $8(23.5)$ & 0.067 \\
\hline Usage of metformin (\%) & $320(84.4)$ & $49(44.5)$ & $* *$ & $<0.001$ \\
\hline Use of DPP4i (\%) & $164(43.3)$ & $51(46.4)$ & $13(38.2)$ & 0.69 \\
\hline Use of SGLT2i (\%) & $43(11.3)$ & $* *$ & $0(0.0)$ & $<0.001$ \\
\hline T-Cholesterol (mg/dl) & $145.1(30.8)$ & $143.6(26.2)$ & $141.0(25.3)$ & 0.70 \\
\hline LDL (mg/dl) & $87.4(25.1)$ & $83.8(26.0)$ & $82.4(20.8)$ & 0.27 \\
\hline Triglyceride (mg/dl) & $136.6(109.4)$ & $162.8(103.0)$ & $157.7(104.7)$ & 0.060 \\
\hline hs-CRP (mg/dl) & $0.21(0.32)$ & $0.47(1.12)$ & $0.33(0.61)$ & $<0.001^{*}$ \\
\hline
\end{tabular}

Table 2 Immune cell number and phenotype comparisons by CKD stage

\begin{tabular}{|c|c|c|c|c|}
\hline & eGFR $\geq 60(n=379)$ & Stage 3 CKD $(n=110)$ & Stage $4 / 5$ CKD $(n=34)$ & $p$ value \\
\hline Number CD3+ & $1023.2(418.1)$ & $964.8(447.5)$ & $788.0(311.2)$ & $0.005^{*}$ \\
\hline Number CD4+ & $604.4(277.0)$ & $555.3(248.7)$ & $450.1(200.7)$ & $0.003^{*}$ \\
\hline Number CD8+ & $282.8(158.6)$ & $293.1(190.4)$ & $221.4(134.0)$ & 0.079 \\
\hline CD4+ $\mathrm{T}_{\text {NAIVE }}(\%)$ & $37.7(14.1)$ & $38.6(15.6)$ & $39.1(16.7)$ & 0.78 \\
\hline $\mathrm{CD} 4+\mathrm{T}_{\mathrm{EFF}}(\%)$ & $3.2(3.9)$ & $3.3(3.8)$ & $4.7(4.8)$ & 0.093 \\
\hline CD4+ CD127+ (\%) & $92.4(5.3)$ & $90.7(6.9)$ & $88.4(7.1)$ & $<0.001^{*}$ \\
\hline CD4+ CD28- (\%) & $7.1(8.3)$ & $9.0(9.1)$ & $7.9(6.3)$ & 0.12 \\
\hline CD4+ CD57+ (\%) & $4.2(4.8)$ & $5.3(5.9)$ & $5.1(5.6)$ & 0.096 \\
\hline CD8+ $\mathrm{T}_{\text {NAIVE }}(\%)$ & $22.9(12.5)$ & $19.9(12.3)$ & $18.5(10.4)$ & $0.02^{*}$ \\
\hline CD8+ $T_{\text {EFF }}(\%)$ & $31.5(17.5)$ & $38.8(19.4)$ & 38.9 (19.6) & $<0.001^{*}$ \\
\hline CD8+ CD127+ (\%) & $55.1(16.3)$ & $46.9(16.6)$ & $47.8(14.5)$ & $<0.001^{*}$ \\
\hline CD8+ CD28- (\%) & $45.2(17.7)$ & $54.8(17.2)$ & $53.8(18.2)$ & $<0.001^{*}$ \\
\hline CD8+ CD57+ (\%) & $27.3(17.4)$ & $33.1(20.5)$ & $33.7(18.0)$ & $0.003^{*}$ \\
\hline Number CD68+ & $378.0(146.7)$ & $412.0(162.8)$ & $383.2(159.4)$ & 0.12 \\
\hline Monocyte 1 (\%) & $75.2(8.9)$ & $75.3(9.9)$ & $76.5(9.1)$ & 0.74 \\
\hline Monocyte 2 (\%) & $3.7(1.7)$ & $3.8(2.4)$ & $3.7(1.9)$ & 0.76 \\
\hline Monocyte 3 (\%) & $10.7(4.7)$ & $10.8(7.0)$ & $10.2(5.7)$ & 0.85 \\
\hline
\end{tabular}

Immune cell profiles were compared between eGFR groups. $P$ values were calculated using one-way ANOVA. For cell subsets, the percentage of the mother cell population was used for comparison instead of cell numbers. Values are expressed as means (SD). * $p$ value $<0.05$. eGFR, estimated glomerular filtration rate derived from the CKD-EPI formula. Stage 3 CKD, eGFR between 30 and 60; stage 4 CKD, eGFR between 15 and 30; stage 5 CKD, eGFR less than 15. Monocyte 1: classical monocytes. Monocyte 2: intermediate monocytes. Monocyte 3: non-classical monocyte 
Table 3 Immune cell number and phenotype by CKD stage in age and sex-adjusted regression models

\begin{tabular}{|c|c|c|c|c|c|}
\hline & \multicolumn{2}{|c|}{$\begin{array}{l}\text { Stage } 3 \text { CKD } \\
\text { versus } \\
\text { eGFR } \geq 60\end{array}$} & \multicolumn{2}{|c|}{$\begin{array}{l}\text { Stage } 4 / 5 \text { CKD } \\
\text { versus } \\
\text { eGFR } \geq 60\end{array}$} & \multirow[t]{2}{*}{$\begin{array}{l}\mathrm{p} \text { for } \\
\text { trend }\end{array}$} \\
\hline & $B$ & $p$ value & $B$ & $p$ value & \\
\hline Number CD3+ & -18.09 & 0.68 & -163.13 & $0.021^{*}$ & 0.053 \\
\hline Number CD4+ & -20.49 & 0.46 & -110.87 & $0.013^{*}$ & $0.024^{*}$ \\
\hline Number CD8+ & 21.21 & 0.21 & -37.09 & 0.17 & 0.73 \\
\hline CD4+ $\mathrm{T}_{\text {NAIVE }}(\%)$ & 1.75 & 0.29 & 2.19 & 0.41 & 0.23 \\
\hline CD4+ $T_{\text {EFF }}(\%)$ & -0.31 & 0.33 & 1.09 & $0.032^{*}$ & 0.29 \\
\hline CD4+ CD127+ (\%) & -0.72 & 0.19 & -3.21 & $<0.001^{*}$ & $0.001^{*}$ \\
\hline CD4+ CD28- (\%) & 0.7 & 0.33 & 1.1 & 0.33 & 0.21 \\
\hline CD4+ CD57+ (\%) & 0.32 & 0.47 & 0.32 & 0.65 & 0.46 \\
\hline $\mathrm{CD} 8+\mathrm{T}_{\text {NAIVE }}(\%)$ & -2.59 & $0.045^{*}$ & -3.24 & 0.12 & $0.024^{*}$ \\
\hline$C D 8+T_{E F F}(\%)$ & 4.96 & $0.015^{*}$ & 4.9 & 0.14 & $0.015^{*}$ \\
\hline CD8+ CD127+ (\%) & -4.66 & $0.009^{*}$ & -3.59 & 0.21 & $0.019^{*}$ \\
\hline CD8+ CD28- (\%) & 6.04 & $0.002^{*}$ & 5.14 & 0.1 & $0.004^{*}$ \\
\hline CD8+ CD57+ (\%) & 3.45 & $0.041^{*}$ & 4.6 & 0.089 & $0.018^{*}$ \\
\hline Number CD68+ & 23.5 & 0.16 & 0.43 & 0.99 & 0.45 \\
\hline Monocyte 1 (\%) & 0.54 & 0.55 & 2.17 & 0.13 & 0.15 \\
\hline Monocyte 2 (\%) & -0.19 & 0.29 & -0.25 & 0.38 & 0.22 \\
\hline Monocyte 3 (\%) & -0.78 & 0.13 & -1.24 & 0.13 & 0.053 \\
\hline
\end{tabular}

Age and sex-adjusted multivariable regression models and trend analyses to test the independent associations between immune profile and CKD stages. ${ }^{*}: P$ value $<0.05$. eGFR, estimated glomerular filtration rate derived from the CKD-EPI formula. Stage 3 CKD, eGFR between 30 and 60 ; stage 4 CKD, eGFR between 15 and 30; stage 5 CKD, eGFR less than 15. Monocyte 1: classical monocytes. Monocyte 2: intermediate monocytes. Monocyte 3: non-classical monocyte

with normal eGFR $>60 \mathrm{ml} / \mathrm{min}(N=138)$. The mean age of the age-matched sample was increased to $64.7 \pm 9.32$. We re-examined the relationship between CKD stages and immunophenotypes using this age-matched comparison group while still adjusting for age and sex. The results were similar to the main analysis (supplementary Table 2) suggesting that the relationship between CKD stages and immunophenotypes was independent of age.

These results indicate the existence of independent effects of CKD on $\mathrm{T}$ lymphocyte immunosenescence, and the effects emerge since stage $3 \mathrm{CKD}$ and the phenotypical changes are more pronounced in the $\mathrm{CD} 8^{+}$ $\mathrm{T}$ cell compartment.

\section{Neither the level of albuminuria nor that of serum glucose level significantly affects immunosenescence}

Two recent reports found that level of senescent $\mathrm{T}$ cells predicts the future development of hyperglycemia [23, 24]. Thus, we analyzed the effects of hyperglycemia on immunosenescence. No effects were found for glycated hemoglobin and glucose level in the immune subsets tested (supplementary Table 3 and 4). In addition, no effects were found for duration of diabetes on immunosenescence (supplementary Table 5). We further analyzed the effects of specific types of oral hypoglycemia agent and insulin usage on immunosenescence (supplementary Table 6).
However, none of the medications were associated with immunosenescence. Blood sugar level and medication used to control hyperglycemia were significantly different among three groups of patients. We further adjusted for blood glucose level and medication use in the regression models to understand if these factors modulate the effects of CKD on immunosenescence. The associations between CKD stages and lymphocyte immunosenescence remained consistent with the main analyses even after adjustment for glucose level (supplementary Table 7) as well as HbA1c and specific medication usage (data not shown).

Decline of renal function in diabetes is aggravated by the level of albuminuria. Nevertheless, when level of albuminuria was analyzed, only the $\mathrm{CD} 8^{+} \mathrm{CD} 28^{-}$cells were found to increase with albuminuria with statistical significance (supplementary Table $8, p=0.048$ ). Since changes in other related cell subsets were not concomitantly significantly affected with albuminuria, we conclude that the effects of albuminuria on immunosenescence is much less prominent than the effects of the decrease in eGFR.

\section{Body mass index impacts immunosenescence}

Finally, we investigated the effects of body mass index (BMI) on immunosenescence. BMI is closely related to thymic function in patients receiving kidney transplantation [25]. Enhanced $\mathrm{T}$ cell differentiation was also 
observed in children with excess BMI [26]. Whether BMI is associated with immunosenescence in diabetic adults is unknown. Because CKD has the potential to affect patients' nutritional status and BMI, we investigated the effects of BMI in two regression models. As shown in Table 4, BMI positively associated with the increase in $\mathrm{T}$ cells with advanced differentiation but negatively associated with frequencies of naïve $\mathrm{T}$ cells, especially in the $\mathrm{CD}^{+}$compartment. While $\mathrm{CD} 4^{+} \mathrm{T}$ cells exhibit similar trend, most differences did not reach statistical significance. BMI did not impact on monocyte phenotypes in both models.

\section{Discussion}

The current study investigated the emergence and clinical correlation of immunosenescence in type 2 diabetic patients. To our knowledge, this is the largest cohort study focusing on immune changes in type 2 diabetic patients. Although we and others have proven that immunosenescence is an important feature of dialysis patients, this is the first evidence that immunosenescence occurs as early as stage 3 CKD during renal function decline and thus, suggests the mechanism of immunosenescence does not just occur after uremia or dialysis treatment but rather represents the chronic, collective physiological changes patients experience during the progression of CKD. In contrast, none of duration of diabetes, usage of specific oral hypoglycemic agent and nor the extent of albuminuria was significantly associated with immunosenescence.

A significant increase in $\mathrm{T}$ cell immunosenescence, as based on multiple markers (including naïve cell markers CD27/CD45RO, CD28, CD127 and CD57), is observed

Table 4 Effects of BMI on immunosenescence in multivariableadjusted regression models

\begin{tabular}{|c|c|c|c|c|}
\hline & \multicolumn{2}{|c|}{$\begin{array}{l}\text { Model } 1 \\
\text { Adjusted for Age, Sex }\end{array}$} & \multicolumn{2}{|c|}{$\begin{array}{l}\text { Model } 2 \\
\text { Adjusted for Age, } \\
\text { Sex, CKD status }\end{array}$} \\
\hline & $B$ & $p$ value & $\bar{B}$ & $p$ value \\
\hline CD4+ T & -0.13 & 0.36 & -0.19 & 0.20 \\
\hline CD4+ $T_{\text {EFF }}(\%)$ & 0.0062 & 0.82 & 0.0081 & 0.77 \\
\hline CD4+ CD127+ (\%) & -0.056 & 0.26 & -0.038 & 0.44 \\
\hline CD4+ CD28- (\%) & 0.082 & 0.19 & 0.073 & 0.25 \\
\hline CD4+ CD57+ (\%) & 0.027 & 0.48 & 0.023 & 0.56 \\
\hline CD8+ T $_{\text {NAIVE }}(\%)$ & -0.20 & 0.083 & -0.17 & 0.15 \\
\hline CD8+ $T_{\text {EFF }}(\%)$ & 0.25 & 0.17 & 0.20 & 0.28 \\
\hline CD8+ CD127+ (\%) & -0.25 & 0.12 & -0.19 & 0.23 \\
\hline CD8+ CD28- (\%) & 0.37 & $0.033^{*}$ & 0.30 & 0.087 \\
\hline CD8+ CD57+ (\%) & 0.42 & $0.0049^{*}$ & 0.37 & $0.017^{*}$ \\
\hline
\end{tabular}

Multivariable regression models to test the independent associations between immune profile and BMI. *: $P$ value $<0.05$. BMI: Body Mass Index. Monocyte 1: classical monocytes. Monocyte 2: intermediate monocytes. Monocyte 3: non-classical monocyte in type 2 diabetic patients with eGFR below $60 \mathrm{ml} / \mathrm{min}$. At the same time, significant decreases in total $\mathrm{T}$ cell numbers as well as CD4+ and CD8+ T cell numbers also occur. Due to the decrease of $\mathrm{T}$ cell numbers and the increased percentages of cells with immunosenescent features, we determine that patients with CKD exhibit both qualitative as well as quantitative changes in their immunity which potentially leads to suboptimal responses to new infections and vaccinations.

Numerous past studies indicated that the risk of cardiovascular disease increases dramatically with declining renal function. It has been suggested that the renal failure-related risk is independent from traditional cardiovascular risk factors. Among the atypical cardiovascular risk factors associated with CKD, inflammation is probably the most consistent and strongest, and its role in this disease has been confirmed in many studies [27, 28]. Furthermore, inflammation is involved in almost all aging-related chronic diseases and thus, the concept of inflammaging is at the nexus of all the other mechanisms of aging [29]. In this regard, chronic inflammation is also closely related to immunosenescence. For example, the etiology of chronic inflammation is partially due to the secretory phenotype of senescent somatic and immune cells. Senescent immune cells spontaneously express proinflammatory cytokines without antigen stimulation [30]. In turn, an inflammatory milieu promotes the generation of senescent $\mathrm{CD} 28^{-} \mathrm{T}$ cells [31]. It is possible that inflammation and the accumulation of senescent immune cells collaboratively promote atherosclerosis. In this report, we demonstrate that immunosenescence parallels the elevated hs-CRP level seen in type 2 diabetic patients with renal function decline since stage $3 \mathrm{CKD}$, and thus implicates the potential collaborative contribution of inflammaging to the development of cardiovascular complications in type 2 diabetes.

Our results indicate that as CKD progress, progressive decrease in circulatory CD3+ $\mathrm{T}$ cells can be observed and the effect on cell number is more pronounced among CD4+ cells. This is bewildering because both $\mathrm{CD} 4+$ and $\mathrm{CD} 8+\mathrm{T}$ cell numbers are decreased in ESRD [12]. In CKD, two studies [32, 33] found circulatory $\mathrm{CD} 3+\mathrm{T}$ cell numbers are decreased and both showed the decrease is more pronounced in $\mathrm{CD} 4+\mathrm{T}$ cells, consistent with ours. The reason behind such differences between $\mathrm{CD} 4+$ and $\mathrm{CD} 8+\mathrm{T}$ cells remain unknown; although it may be due to the relative deficiency of IL-7 in CKD patients [32] and the stronger dependence of CD4+ T cells on IL-7 for homeostasis [34]. Another possibility is the preferential expansion of CMV-specific CD8+ $\mathrm{T}$ cells in patients with CKD or ESRD, as our recent study suggested that CMV might be less wellcontrolled in ESRD patients [13]. As a result, while quantitative changes are more pronounced in $\mathrm{CD} 4^{+} \mathrm{T}$ 
cells, qualitative changes might be more evident in the CD8+ compartment. Indeed, our recent report in ESRD patients [21] and others' report in CKD patients [33] also showed the aging-related phenotypic changes are more pronounced in the $\mathrm{CD}^{+}$compartment than in $\mathrm{CD}^{+} \mathrm{T}$ cells. This is further demonstrated in the current study by the concordant decrease of $\mathrm{CD}^{+} \mathrm{T}_{\mathrm{NA}}$ IVE and $\mathrm{CD}^{+} \mathrm{CD} 127^{+}$cells along with the increase of $\mathrm{CD}^{+} \mathrm{T}_{\mathrm{E}}, \mathrm{CD}^{+} \mathrm{CD} 28^{-}$and $\mathrm{CD} 8^{+} \mathrm{CD} 57^{+}$cells in patients with CKD stage 3 . Regretfully, we did not find that patients with stage $4 / 5 \mathrm{CKD}$ have more $\mathrm{CD} 8^{+} \mathrm{CD} 28^{-}$or $\mathrm{CD} 28^{+} \mathrm{CD} 57^{+}$cells compared to stage 3 CKD patients; however, because the cohort contains relatively fewer CKD stage $4 / 5$ patients, the comparison might be underpowered. We also found that CKD stage 3 patients simultaneously exhibited higher level of hs-CRP than stage $4 / 5$ patients. The lack of dose effects of severity of renal failure on immunosenescence probably also reflects, the extent of inflammation and inflammaging changes in different levels of CKD.

Other factors also potentially modulate the effects of decreased renal function on enhanced immunosenescence. Mechanisms potentially contribute to immunosenescence during renal function decline includes decreased insulinlike growth factor 1 signaling pathway, decreased vitamin D level and accumulation of advanced glycation end products, because these factors are disturbed in CKD and found to be involved in the premature aging phenotype in certain organ systems. Among these, vitamin D in old individuals was found to correlate with some features of the immune system, mainly in the $\mathrm{CD} 8^{+} \mathrm{T}$ cell compartment [35]. The role of these factors in promoting immunosenescence requires further investigation.

Our study also identified the effects of BMI on advanced $\mathrm{T}$ cell differentiation, especially in the $\mathrm{CD}^{+}$compartment (Table 4). Such effect can still be observed after controlling for CKD status. Interestingly, a previous study found that plasma from obese individuals can induce the loss of CD28 expression in PBMCs from healthy individuals with normal BMI. Other features of senescence, including decreased expression of $\gamma-\mathrm{H} 2 \mathrm{AX}$ and p53, can also be observed [36]. Importantly, the effects of obesity on immunosenescence may be reversible, as exercise has been shown to improve immunosenescence [37].

In our study, aging-related subset distribution changes could only be observed in the T lymphocyte compartment, while the monocyte subset distribution and number remained mostly unchanged with renal function decline. Studies of the impact of aging on the function and homeostasis of human monocytes are limited in number and have yielded conflicting results. While some studies had shown that aging influences monocyte subset distribution [38, 39], others found that aging does not have an effect on the surface phenotype of monocytes in non-stimulated conditions
[40]. Our current study indicates that in type 2 diabetic patients, aging is associated with the increase of proinflammatory intermediate and non-classical monocyte subsets. On the other hand, we did not observe significant effects of renal function on the monocyte compartment in type 2 diabetic patients. A previous study indicated that monocyte functionality in response to stimulation of pattern recognition receptors changes during aging [41]; however, we did not measure the response of monocytes in vitro in this study. Thus, monocytes might undergo more significant changes after dialysis treatment since intermediate $\mathrm{CD} 14^{++} \mathrm{CD} 16^{+}$monocytes and non-classical monocytes are both increased in hemodialysis patients [21].

Our study has several additional limitations. First, while the seroprevalence of cytomegalovirus (CMV) in the study group is not known, the overall CMV seroprevalence in Taiwan is known to be very high. In addition, based on our recent study, the seroprevalence of CMV is almost $99 \%$ in this age group in Taiwan [42]. It is possible that effects of renal failure can only be observed in patients infected with CMV, as evidenced in a recent publication [33] and analyzed in our recent review [13]. Secondly, because this study only includes diabetic patients, our findings may not be generalizable to non-diabetic patients with CKD. Finally, longitudinal follow-up will be necessary to determine if the progression of immunosenescence precedes or parallels the deterioration of renal function.

\section{Conclusion}

Type 2 diabetic patients exhibit significant aging-related immune changes in the T cell compartment in parallel with enhanced systemic inflammation as eGFR declines to less than $60 \mathrm{ml} / \mathrm{min}$ (CKD stage 3). Immunosenescence positively associates with higher BMI. This finding has important implications for further intervention studies and suggests that, in type 2 diabetic patients, therapeutic measures aimed at modulating immunosenescence and inflammation should be initiated prior to the development of stage 3 CKD.

\section{Supplementary information}

Supplementary information accompanies this paper at https://doi.org/10. 1186/s12979-020-00200-1.

\footnotetext{
Additional file 1: Supplementary Figure 1 Representative flow cytometry staining of immunophenotypin. Supplementary Table 1 Correlations between Immune cell number and phenotype with age. Supplementary Table $\mathbf{2}$ Immune cell number and phenotype by CKD stage in age and sex-adjusted regression models in age-matched samples Supplementary Table 3 Effects of HbA1c on immune cell subsets in multivariable-adjusted regression models. Supplementary Table 4 Effects of glucose level on immune cell subsets in multivariable-adjusted regression model. Supplementary Table $\mathbf{5}$ Effects of duration of diabetes on immune cell subsets in multivariable-adjusted regression models. Supplementary Table 6 Effects of specific glucose-lowering medication usage on immune cell subsets in multivariable-adjusted
} 
regression models. Supplementary Table $\mathbf{7}$ Effects of CKD on immune cell subsets in age, sex and glucose level-adjusted regression models. Supplementary Table 8 Immune cell number and phenotype comparisons by albuminuria levels.

\section{Abbreviations}

ESRD: End-stage renal disease; CKD: Chronic kidney disease

CVD: Cardiovascular disease; eGFR: Estimated glomerular filtration rate; BMI: Body mass index; CMV: Cytomegalovirus; hs-CRP: High-sensitivity C-reactive protein

\section{Acknowledgements}

The authors thank Ms. Priscilla Tsai for her expertise and assistance with multicolor flow cytometry and additional samples provided by the Far Eastern Memorial Hospital Biobank for establishing experimental technical controls.

\section{Authors' contributions}

Y.L.C., Y.F.C, Y.S.P., J.Y.J. and K.H.S. initiated the study and major experiments; Y.S.P. and J.Y.J. recruited study participants; R.W.H., I.Y.C., K.H.S., S.Y.P. and F.J.Y. carried out experiments; Y.F.C., F.J.Y., Y.L.C. and S.Y.P. analyzed experiments; Y.L.C., Y.F.C., and F.J.Y. edited the manuscript; Y.L.C. and Y.F.C. wrote the manuscript. All the authors participated in the reading and completion of this manuscript. The author(s) read and approved the final manuscript.

\section{Funding}

This work was supported by Far Eastern Memorial Hospital internal grant FEMH-PI20180002 awarded to Dr. Yu-Sen Peng and Ministry of Science and Technology grant MOST 106-2314-B-418-008-MY3 awarded to Dr. Yen-Ling Chiu.

\section{Availability of data and materials}

All relevant data are within the manuscript and its supporting Information files.

\section{Ethics approval and consent to participate}

The study was approved by the Far Eastern Memorial Hospital's institutional ethical committee (FEMH 107032-F) and written informed consent was acquired from all participants.

\section{Consent for publication}

All authors consent to the publication of this final version of the manuscript.

\section{Competing interests}

Non-declared. The authors declare that the research was conducted in the absence of any commercial or financial relationships that serves as a potential conflict of interest. The results presented in this paper have not been published previously in whole or part, except in abstract format.

\section{Author details}

${ }^{1}$ Graduate Program in Biomedical Informatics, Department of Computer Science and Engineering, College of Informatics, Yuan Ze University, Taoyuan, Taiwan. ${ }^{2}$ Division of Nephrology, Department of Medicine, Far Eastern Memorial Hospital, New Taipei City, Taiwan. ${ }^{3}$ Graduate Institute of Clinical Medicine, National Taiwan University College of Medicine, Taipei, Taiwan. ${ }^{4}$ Center for General Education, Lee-Ming Institute of Technology, New Taipei City, Taiwan. ${ }^{5}$ Graduate Institute of Immunology, National Taiwan University College of Medicine, Taipei, Taiwan. ${ }^{6}$ Department of Medicine, National Taiwan University Hospital Yun Lin Branch, Douliu, Taiwan. ${ }^{7}$ School of Big Data Management, Soochow University, Taipei, Taiwan. ${ }^{8}$ Division of Endocrinology and Metabolism, Department of Medicine, Far Eastern Memorial Hospital, New Taipei City, Taiwan. ${ }^{9}$ Department of Applied Cosmetology, Lee-Ming Institute of Technology, New Taipei City, Taiwan. ${ }^{10}$ Department of Healthcare Administration, Oriental Institute of Technology, New Taipei City, Taiwan. ${ }^{11}$ Institute of Public Health, School of Medicine, National Yang-Ming University, Taipei, Taiwan.
Received: 17 December 2019 Accepted: 17 September 2020

Published online: 20 October 2020

\section{References}

1. Doshi SM, Friedman AN. Diagnosis and Management of Type 2 diabetic kidney disease. Clin J Am Soc Nephrol. 2017;12(8):1366-73.

2. Ogurtsova K, da Rocha Fernandes JD, Huang Y, Linnenkamp U, Guariguata L, Cho NH, Cavan D, Shaw JE, Makaroff LE. IDF diabetes atlas: global estimates for the prevalence of diabetes for 2015 and 2040. Diabetes Res Clin Pract. 2017;128:40-50.

3. Leon BM, Maddox TM. Diabetes and cardiovascular disease: epidemiology, biological mechanisms, treatment recommendations and future research. World J Diabetes. 2015;6(13):1246-58.

4. Knapp S. Diabetes and infection: is there a link?--a mini-review. Gerontology 2013;59(2):99-104.

5. Singh A, Donnino R, Weintraub H, Schwartzbard A. Effect of strict glycemic control in patients with diabetes mellitus on frequency of macrovascular events. Am J Cardiol. 2013;112(7):1033-8.

6. Abu-Ashour W, Twells LK, Valcour JE, Gamble JM. Diabetes and the occurrence of infection in primary care: a matched cohort study. BMC Infect Dis. 2018;18(1):67.

7. Libby P, Lichtman AH, Hansson GK. Immune effector mechanisms implicated in atherosclerosis: from mice to humans. Immunity. 2013;38(6): 1092-104.

8. Aiello $A E$, Chiu YL, Frasca D. How does cytomegalovirus factor into diseases of aging and vaccine responses, and by what mechanisms? GeroScience. 2017;39(3):261-71

9. Larbi A, Franceschi C, Mazzatti D, Solana R, Wikby A, Pawelec G. Aging of the immune system as a prognostic factor for human longevity. Physiology. 2008:23:64-74.

10. McElhaney JE, Effros RB. Immunosenescence: what does it mean to health outcomes in older adults? Curr Opin Immunol. 2009:21(4):418-24.

11. Fulop T, Larbi A, Dupuis G, Le Page A, Frost EH, Cohen AA, Witkowski JM, Franceschi C. Immunosenescence and Inflamm-aging as two sides of the same coin: friends or foes? Front Immunol. 2017:8:1960.

12. Betjes MG. Immune cell dysfunction and inflammation in end-stage renal disease. Nat Rev Nephrol. 2013;9(5):255-65.

13. Yang TO, Chuang YF, Chiu YL. T-cell aging in end-stage renal disease: an evolving story with CMV. Med Microbiol Immunol. 2019;208(3-4): 281-7.

14. Weyand CM, Fulbright JW, Goronzy JJ. Immunosenescence, autoimmunity, and rheumatoid arthritis. Exp Gerontol. 2003;38(8):833-41.

15. Pawelec G, Larbi A, Derhovanessian E. Senescence of the human immune system. J Comp Pathol. 2009;142(Suppl 1):S39-44.

16. Nikolich-Zugich J. Aging of the T cell compartment in mice and humans: from no naive expectations to foggy memories. J Immunol. 2014;193(6):2622-9.

17. Ammirati $E$, Cianflone $D$, Vecchio V, Banfi M, Vermi AC, De Metrio M, Grigore L, Pellegatta F, Pirillo A, Garlaschelli K, et al. Effector memory T cells are associated with atherosclerosis in humans and animal models. J Am Heart Assoc. 2012:1(1):27-41.

18. Yu HT, Youn JC, Kim JH, Seong YJ, Park SH, Kim HC, Lee WW, Park S, Shin EC. Arterial Stiffness Is Associated With Cytomegalovirus-Specific Senescent CD8(+) T Cells. J Am Heart Assoc. 2017;6(9):e006535.

19. Heine GH, Ulrich C, Seibert E, Seiler S, Marell J, Reichart B, Krause M, Schlitt A, Kohler H, Girndt M. CD14(++)CD16+ monocytes but not total monocyte numbers predict cardiovascular events in dialysis patients. Kidney Int. 2008; 73(5):622-9.

20. Rogacev KS, Cremers B, Zawada AM, Seiler S, Binder N, Ege P, GrosseDunker G, Heisel I, Hornof F, Jeken J, et al. CD14++CD16+ monocytes independently predict cardiovascular events: a cohort study of 951 patients referred for elective coronary angiography. J Am Coll Cardiol. 2012;60(16): $1512-20$.

21. Chiu YL, Shu KH, Yang FJ, Chou TY, Chen PM, Lay FY, Pan SY, Lin CJ, Litjens $\mathrm{NHR}$, Betjes MGH, et al. A comprehensive characterization of aggravated aging-related changes in T lymphocytes and monocytes in end-stage renal disease: the iESRD study. Immun Ageing. 2018;15:27.

22. Alpert A, Pickman Y, Leipold M, Rosenberg-Hasson Y, Ji X, Gaujoux R, Rabani $H$, Starosvetsky E, Kveler K, Schaffert S, et al. A clinically meaningful metric of immune age derived from high-dimensional longitudinal monitoring. Nat Med. 2019;25(3):487-95 
23. Lee YH, Kim SR, Han DH, Yu HT, Han YD, Kim JH, Kim SH, Lee CJ, Min BH, Kim DH, et al. Senescent T cells predict the development of hyperglycemia in humans. Diabetes. 2019;68(1):156-62.

24. Yi HS, Kim SY, Kim JT, Lee YS, Moon JS, Kim M, Kang YE, Joung KH, Lee JH, Kim HJ, et al. T-cell senescence contributes to abnormal glucose homeostasis in humans and mice. Cell Death Dis. 2019;10(3):249.

25. Ducloux D, Courivaud C, Bamoulid J, Crepin T, Gaiffe E, Laheurte C, Vauchy C, Rebibou JM, Saas P, Borot S. Immune phenotype predicts new onset diabetes after kidney transplantation. Hum Immunol. 2019;80(11):937-42.

26. Spielmann G, Johnston CA, O'Connor DP, Foreyt JP, Simpson RJ. Excess body mass is associated with $T$ cell differentiation indicative of immune ageing in children. Clin Exp Immunol. 2014;176(2):246-54

27. Pearson TA, Mensah GA, Alexander RW, Anderson JL, Cannon RO 3rd, Criqui M, Fadl YY, Fortmann SP, Hong Y, Myers GL, et al. Markers of inflammation and cardiovascular disease: application to clinical and public health practice: a statement for healthcare professionals from the Centers for Disease Control and Prevention and the American Heart Association. Circulation. 2003;107(3):499-511.

28. Menon V, Greene T, Wang X, Pereira AA, Marcovina SM, Beck GJ, Kusek JW, Collins AJ, Levey AS, Sarnak MJ. C-reactive protein and albumin as predictors of all-cause and cardiovascular mortality in chronic kidney disease. Kidney Int. 2005;68(2):766-72.

29. Franceschi C, Garagnani P, Parini P, Giuliani C, Santoro A. Inflammaging: a new immune-metabolic viewpoint for age-related diseases. Nat Rev Endocrinol. 2018;14(10):576-90.

30. Vicente R, Mausset-Bonnefont AL, Jorgensen C, Louis-Plence P, Brondello $J M$. Cellular senescence impact on immune cell fate and function. Aging Cell. 2016;15(3):400-6.

31. Macaulay R, Akbar AN, Henson SM. The role of the T cell in age-related inflammation. Age (Dordr). 2013;35(3):563-72.

32. Litjens NH, van Druningen CJ, Betjes MG. Progressive loss of renal function is associated with activation and depletion of naive T lymphocytes. Clin Immunol. 2006;118(1):83-91.

33. Crepin T, Legendre M, Carron C, Vachey C, Courivaud C, Rebibou JM, Ferrand C, Laheurte C, Vauchy C, Gaiffe E, et al. Uraemia-induced immune senescence and clinical outcomes in chronic kidney disease patients. Nephrol Dial Transplant. 2020;35(4):624-32.

34. Fry TJ, Connick E, Falloon J, Lederman MM, Liewehr DJ, Spritzler J, Steinberg SM, Wood LV, Yarchoan R, Zuckerman J, et al. A potential role for interleukin-7 in T-cell homeostasis. Blood. 2001:97(10):2983-90.

35. Alves AS, Ishimura ME, Duarte $Y A O$, Bueno V. Parameters of the immune system and vitamin D levels in old individuals. Front Immunol. 2018;9:1122.

36. Parisi MM, Grun LK, Lavandoski P, Alves LB, Bristot IJ, Mattiello R, Mottin CC, Klamt $\mathrm{F}$, Jones $\mathrm{MH}$, Padoin $\mathrm{AV}$, et al. Immunosenescence induced by plasma from individuals with obesity caused cell signaling dysfunction and inflammation. Obesity (Silver Spring). 2017;25(9):1523-31.

37. Turner JE. Is immunosenescence influenced by our lifetime "dose" of exercise? Biogerontology. 2016;17(3):581-602.

38. Merino A, Buendia P, Martin-Malo A, Aljama P, Ramirez R, Carracedo J. Senescent CD14+CD16+ monocytes exhibit proinflammatory and proatherosclerotic activity. J Immunol. 2011;186(3):1809-15.

39. Hearps AC, Martin GE, Angelovich TA, Cheng WJ, Maisa A, Landay AL, Jaworowski A, Crowe SM. Aging is associated with chronic innate immune activation and dysregulation of monocyte phenotype and function. Aging Cell. 2012;11(5):867-75.

40. Metcalf TU, Cubas RA, Ghneim K, Cartwright MJ, Grevenynghe JV, Richner JM, Olagnier DP, Wilkinson PA, Cameron MJ, Park BS, et al. Global analyses revealed age-related alterations in innate immune responses after stimulation of pathogen recognition receptors. Aging Cell. 2015;14(3):421-32.

41. Metcalf TU, Wilkinson PA, Cameron MJ, Ghneim K, Chiang C, Wertheimer AM, Hiscott JB, Nikolich-Zugich J, Haddad EK. Human monocyte subsets are transcriptionally and functionally altered in aging in response to pattern recognition receptor agonists. J Immunol. 2017;199(4):1405-17.

42. Yang FJ, Shu KH, Chen HY, Chen IY, Lay FY, Chuang YF, Wu CS, Tsai WC, Peng YS, Hsu SP, et al. Anti-cytomegalovirus lgG antibody titer is positively associated with advanced $T$ cell differentiation and coronary artery disease in end-stage renal disease. Immun Ageing. 2018;15:15.

\section{Publisher's Note}

Springer Nature remains neutral with regard to jurisdictional claims in published maps and institutional affiliations.

\section{Ready to submit your research? Choose BMC and benefit from:}

- fast, convenient online submission

- thorough peer review by experienced researchers in your field

- rapid publication on acceptance

- support for research data, including large and complex data types

- gold Open Access which fosters wider collaboration and increased citations

- maximum visibility for your research: over $100 \mathrm{M}$ website views per year

At BMC, research is always in progress.

Learn more biomedcentral.com/submissions 